\title{
Research on the "Three Movements, Two Steps, Three Dimensions" online and offline hybrid teaching model--The Principles of Management as an example
}

\author{
Yijia $\operatorname{Han}^{1}$, Lin Luo* \\ ${ }^{1}$ School of Management, Wuhan University of Technology, Wuhan, China \\ ${ }^{*}$ School of Management, Wuhan University of Technology, Wuhan, China
}

\begin{abstract}
In the current social context, information technology and education teaching are deeply integrated, classroom teaching is gradually changing from "teacher-centred" to "student-centred", and the traditional teaching mode is gradually changing to the online and offline hybrid teaching mode. In this paper, we analyse the limitations of traditional teaching methods and propose a hybrid online and offline teaching model based on the Principles of Management. This model combines online and offline teaching, changes the roles of teachers and students, promotes teaching with learning, and enhances interaction in the teaching process, creates an immersive classroom atmosphere, enhances students' sense of access, realises the leap from Bloom's first-order understanding to higher-order understanding through human-computer interaction, teacher-student interaction and student-student interaction, and cultivates students' structured thinking, critical thinking and innovative thinking.
\end{abstract}

\section{Introduction}

A blended mode of teaching is not just one aspect of blended learning, nor is it a simple overlay of traditional teaching and online teaching. In fact, a blended teaching model in a broad sense is not only a mixture of two or more forms of teaching and learning, such as lectures, discussions, research, cases, e-learning and flipped classrooms, but also includes the deep interaction and integration of various teaching strategies. ${ }^{1}$ Barbara Means found that students learn better in a blended mode than in a traditional face-to-face setting, and that students are more willing to spend more time on independent learning (Figure 1); they also have more access to teaching resources in a blended mode. ${ }^{2}$ combination of the traditional "face-to-face" model and the online "discussion" model, and is growing at an explosive rate. ${ }^{3}$ Therefore, it is of great research value and practical significance to study the online and offline hybrid teaching mode based on Principles of Management to improve the teaching effect of the course and enhance the quality of personnel training.

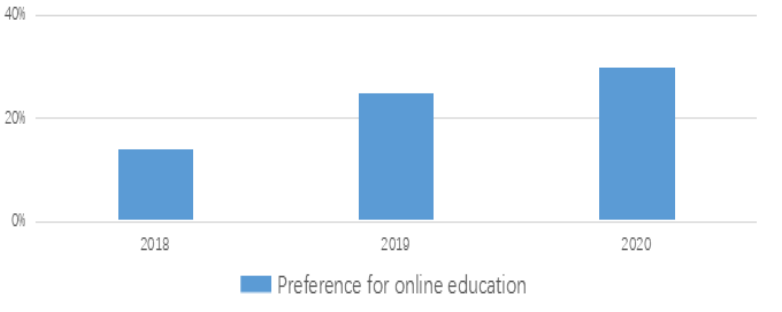

Figure 1 Proportion preferring online education

As a core professional course in the management discipline, Principles of Management is highly theoretical and is the basis for learning professional courses. However, the course still suffers from low class time, insufficient interactivity and lack of student thinking training in the teaching process. The only way to change the current teaching dilemma is to establish a teaching mode adapted to the current social context, using a blended teaching model, promoting a combination of online and offline learning, enhancing teacher-student interaction and applying theory to practice, and the feasibility of blended education, which has been sufficiently verified this year (Figure 2). 


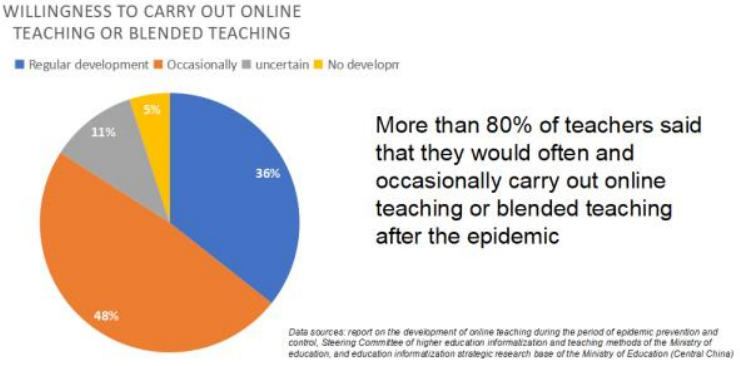

Figure 2 Teachers' willingness to carry out online teaching or blended teaching

\section{Limitations of traditional teaching methods}

\subsection{Isolation of classroom teaching}

Influenced by traditional teaching concepts, most of the classroom teaching in China is "teacher-centred", with the teacher being the initiator and leader of classroom teaching and students in a passive position. There is a lack of effective communication and interaction between students and teachers, and between students and pupils. Although the teacher has more control and freedom, the students often simply take the teacher's ideas into their own hands, without thinking for themselves. As a result, traditional teaching methods like this are often referred to as fill-in-the-blank teaching. This style of teaching inevitably leads to isolation between the teacher and the students in the classroom. A teacher-led classroom only shapes the teacher's thoughts, opinions, language and behaviour and replaces the students' thoughts and opinions, which allows the students' real feelings and ideas to be ignored.

At the same time, the traditional classroom teaching process is mostly dominated by teachers asking questions and students passively answering them, which in turn creates a situation where students are reluctant to answer questions and teachers are embarrassed, and there is less interaction in the classroom for students to actively explore issues and question ideas. This passive acceptance of knowledge and mechanical learning only makes students slaves to their books. Students simply transfer the knowledge from books to their own brains, lacking real understanding and innovation, and in turn the knowledge they learn is difficult to apply, making it difficult for knowledge to become something real for the students themselves. At the same time, many students only focus on memorising knowledge points and strive to get high marks in examinations, often neglecting the development and application of their own abilities, which ultimately leads to many students scoring high and low. The isolation of the classroom has created a gap between students and teachers. The Principles of Management course is based on the theory and basic knowledge of management, and the isolation of the classroom makes students simply memorise the theoretical knowledge points and ignore the practical application of the principles. Classroom teaching ignores its goal of application to practice, isolating knowledge from practice to the detriment of student learning, understanding and application.

\subsection{Singularity of classroom teaching}

The singularity of classroom teaching is firstly reflected in a single teaching objective. The traditional teaching mode is based on the transfer of knowledge, and the unilateral transfer of knowledge cannot meet the needs of students' practice. The single teaching objective neglects students' comprehensive ability to solve complex problems and critical thinking, which is not conducive to students' all-round development. Secondly, influenced by the traditional teaching model, many teachers have a single teaching method and means. For decades, they have been using a blackboard, a book and chalk throughout their teaching activities. The single teaching method lacks creativity and interest, students lack interest and the classroom is not as effective as it could be. In addition, the single location of teaching is also an important feature of the monotony of classroom teaching. In the past, the teaching place was concentrated in the classroom, and students only learnt relevant knowledge in the classroom, neglecting the learning of the course outside the classroom, and course pre-reading and revision were not in place. Principles of Management, as a core professional course, has a lot of course content, and the singularity of classroom teaching has led to slow progress and difficulty in achieving the course objectives.

\subsection{Hollowing out of classroom teaching}

The traditional classroom teaching model is centred on teachers imparting course knowledge points and focusing on book knowledge as a way of believing that this is fundamental to learning science, while ignoring the connection between the scientific world and the reallife world. As a result, in the traditional teaching model, students are often taught with a focus on book knowledge and are detached from reality. However, education in the true sense of the word must start from and be above real life, giving full play to the theoretical guidance of education for practice and its true educational function. In addition, the hollowness of classroom teaching tends to neglect the care for the spiritual world and the life world of students. The lack of communication between teachers and students and between students makes the connection between teaching subjects smaller and the empathy between teachers and students difficult to achieve. The humanistic approach to classroom teaching plays a very important role in the stimulation and conservation of students' vitality, their sound personality, and the acquisition of knowledge and the development of their personal abilities. 


\section{Construction of a blended teaching model based on Principles of Management}

\subsection{Objectives of the blended learning model}

The blended teaching mode aims to enhance "humancomputer interaction, teacher-student interaction and student-student interaction", thereby improving the information literacy of teachers and students, realising real-time display of interactive results and effectively improving students' learning effectiveness. "In addition, the teaching mode effectively enhances students' structured, critical and innovative thinking, strengthens their logical thinking ability, inspires them to think from multiple perspectives and enhances their creative awareness and innovation. In addition, the teaching model effectively enhances students' structured, critical and innovative thinking, strengthens their logical thinking skills, inspires them to think dialectically from multiple perspectives, enhances their creative consciousness and innovative ability, thus realising the transformation from "teacher-centred" to "studentcentred", increases students' participation in the classroom and revitalises the educational vitality contained in the blended teaching model.

\subsection{Content and philosophy of the "three movements, two steps and three dimensions" teaching model}

\subsubsection{Content of the teaching model}

The "Three Movements, Two Steps, Three Dimensions" teaching mode follows the "Trinity" concept of teaching and educating people, based on the national high-quality online open course "Principles of Management", using the digital teaching tool MU classroom, combining the actual situation to explore the "online and offline hybrid" teaching mode, enhancing human-computer interaction, teacher-student interaction and student-student interaction, cultivating students' independent learning ability, improving students' learning responsibility and access. The online and offline hybrid teaching mode enhances human-computer interaction, teacher-student interaction and student-student interaction, cultivates students' independent learning ability, enhances students' sense of responsibility and access to learning, and enables students to achieve the goal of "memorising, understanding and applying" at the initial stage to "analysing, evaluating and creating" at the advanced stage. The programme will enable students to improve and leapfrog from the initial objective of "remembering, understanding and applying" to the higher objective of "analysing, evaluating and creating", train students to think structurally, critically and creatively, solve existing teaching problems, reasonably increase the difficulty of the curriculum and expand its depth, as shown in Figure 3.

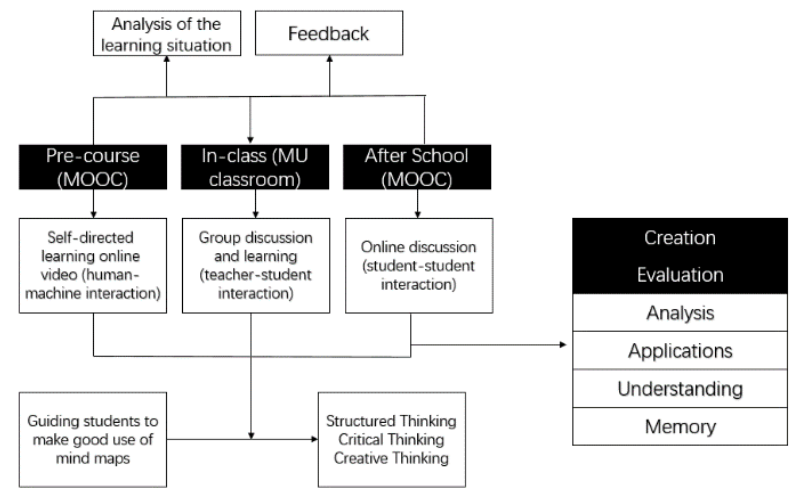

Fig. 3 Content of the "Three Moves, Two Steps, Three Dimensions" teaching model

Each part of the course has its own focus. The precourse online learning focuses on guidance and supervision, helping students to master knowledge points and stimulating their interest and motivation in the process of knowledge exploration; the classroom flip focuses on interaction and application, using the "mu classroom", combining pre-tests, questionnaires, random questions, group discussions and other functions, incorporating the latest management frontier, scientific research and teaching achievements The post-class assignments focus on promoting students' extended thinking and reflection, expanding students' management horizons and the depth and breadth of learning content through guided readings of management masters, online discussions and mutual assessments, and enhancing students' comprehensive ability to solve complex management problems and their entrepreneurial awareness. The post-course assignments focus on expanding students' thinking and reflections.

The whole process of "before-class-in-class-afterclass" focuses on the organic integration of knowledge, ability and quality, precipitating the teaching process and content into curriculum resources, cultivating students' comprehensive ability and advanced thinking in solving complex problems, gradually overcoming the limitations brought about by the small amount of class time and content, promoting the achievement of teaching objectives as far as possible, and thus train students' abilities and thinking, and enhance the higher-order nature of the curriculum; at the same time, improve the cutting-edge and contemporary nature of the curriculum content, enhance the advanced and interactive nature of the teaching format, enhance the inquisitiveness and personalisation of the learning outcomes, promote the formation of students' literacy, and stimulate students' motivation for inquiry; and create contexts that allow students to bring into play and show their own personalities and characteristics. In addition, effective load increases are implemented to enhance academic challenge, allowing students more time for study and reflection as a guarantee of learning outcomes, and to design course content, teaching calendars, teaching activities and course assessments starting from teaching objectives to effectively improve the quality and challenge of the course. 
Under this model, students on the online MOOC teaching platform are given a preview of the relevant concepts, theories and principles in the Principles of Management course to realise human-computer interaction; offline teachers apply theories to each case through case studies and group discussions to realise the leap from theory to practice and realise teacher-student interaction and student-student interaction. Through the combination of online and offline, students can change from "memorising knowledge points and definitions of principles" to "analysing principles of cases" in the process of learning the relevant knowledge of Principles of Management, thus realising Bloom's second-order leap and cultivating students' structural, critical and innovative thinking. This will enable students to develop structural, critical and creative thinking.

\subsubsection{Philosophy of the teaching model}

The "Three Movements, Two Steps, Three Dimensions" teaching mode follows the "three-in-one" concept of teaching and educating people, i.e. knowledge exploration, capacity building and personality development; it absorbs advanced management education concepts at home and abroad, and reconstructs the objectives and content system of the curriculum according to the objectives of knowledge, capacity and quality. The teaching mode follows the concept of "teaching and educating people", i.e. knowledge inquiry, capacity building and personality cultivation; incorporates the advanced management education concepts at home and abroad, and reconstructs the objectives and content system of the course according to the objectives of knowledge, capacity and quality; trains the capacity according to the ability of knowledge application, innovation and entrepreneurship, and critical ability; cultivates the quality cultivation objectives from three aspects, i.e. personality building, professionalism and scientific research consciousness.

\subsection{Features of the teaching model}

\subsubsection{Industry-University-Research Education Model}

Collaborative

"The "Three Movements and Two Steps" model emphasizes "human-computer interaction, teacherstudent interaction, and student-student interaction", and constantly enhances students' participation in the classroom through the three movements. Through teaching and learning activities, students will be able to enhance their second-order objectives, from "memorising, understanding and applying" to "analysing, evaluating and creating", and will be guided to make good use of mind maps to form structured thinking; to inspire students to think critically from multiple perspectives and dialectically; and to develop students' innovative thinking through research for teaching and competition for teaching. In particular, the path of "teaching by competition, learning by application" is integrated into innovation and entrepreneurship education, with scientific research promoting teaching and competition promoting teaching, actively guiding students to participate in innovation and entrepreneurship training programmes and "Internet+" competitions, and cultivating students' innovation and entrepreneurship in the process of innovation and thinking training. In the process of innovative thinking training, students will develop their awareness of innovation and entrepreneurship, teamwork and competition.

Also based on the industry-university-research collaborative education project signed with Santobo Group, combined with the N1N industry-education integration model, the innovation and entrepreneurship management courses are linked to enterprises, and through the Jingbo platform, one end links up university talents and the other end links up research outputs. At the same time, under this model, the curriculum is closely linked to enterprises, so that vivid cases of enterprise management are integrated into the curriculum system; students are recommended to participate in practical training, promoting the deep integration of industry-university-research, promoting the cooperation between universities and enterprises, and achieving winwin cooperation between enterprises and universities.

\subsubsection{Tapping the Civic Elements}

Under the "Three Movements, Two Steps, Three Dimensions" teaching mode, the ideological and political education elements contained in the Principles of Management are fully explored, and the organic integration of ideological and political elements with professional theoretical knowledge is strengthened. The teaching mode is rooted in Chinese management thinking, promoting the excellent traditional culture of the Chinese nation and cultivating students' national sentiments; cultivating students' dedication, contractual spirit, integrity awareness and communication skills around the teaching aspects of organisational culture, social responsibility, morality and ethics, and promoting students' personality development and all-round development. After joining the course Civics, Civics teaching is combined with things that interest students, for example, the Sino-US trade war, the Fan Bingbing tax evasion case, the Xiaomi equity award controversy and other real-life hot issues are closely integrated with management theory. Through case discussion and analysis, students' learning interest is greatly stimulated and the relationship between teachers and students is closely enhanced; through the combination of professional theories and elements of Civics, students' cultural self-confidence is enhanced; through the analysis of real-life hot issues, students are encouraged to put forward their own views and discuss them, and their ability to analyse and solve problems is improved. Students will learn the basics of the course while studying and perceiving the classics of Chinese history and culture to develop their learning, thinking and creative abilities. 


\subsubsection{Information-based teaching}

The "Three Movements, Two Steps, Three Dimensions" teaching mode adopts a variety of informatization teaching tools of "MOOC + MU classroom", relying on national high-quality online open courses, and relying on

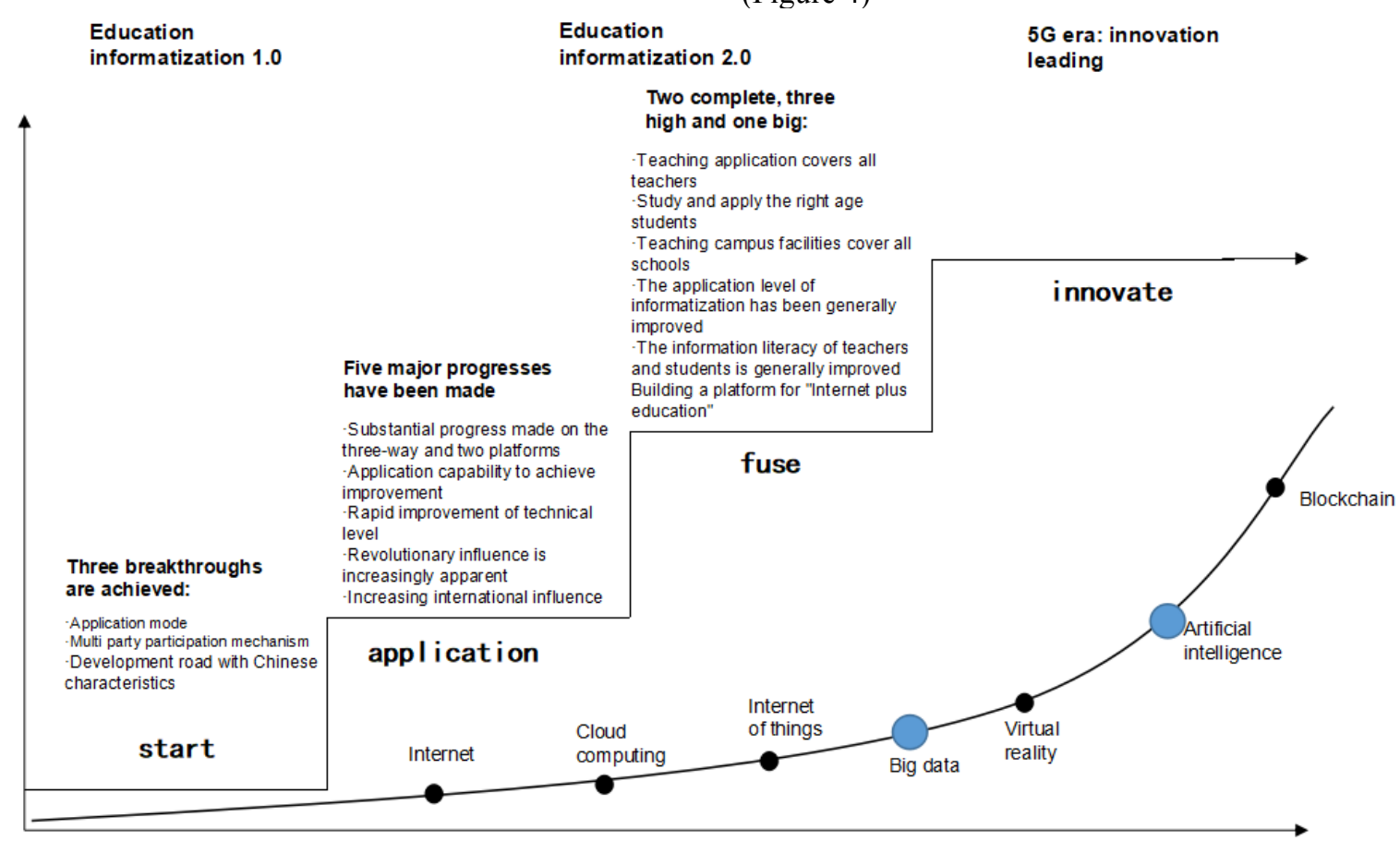

Figure 4 Education informatization 1.0 / 2.0 towards $5 \mathrm{~g}$ Era

\subsection{The value of applying and promoting the teaching model}

The "Three Moves and Two Steps" online and offline hybrid teaching mode will address the current difficulties and priorities in teaching, effectively enhance the interactivity of teaching, increase the difficulty of the course and expand the depth of the course. The "Three Moves" will enable teaching and learning to resonate and increase student engagement and access. In the process of knowledge exploration, capacity building and personality development, students are helped to make leaps and bounds and to improve their thinking skills. In addition, the development of teaching materials, the sharing of resources and the publication of papers will have a positive impact on society and extend the benefits to other courses and other universities.

\subsection{Expected results of the teaching model}

The "Three Moves, Two Steps, Three Dimensions" teaching model enhances the advanced, innovative and challenging nature of the course by comprehensively organising the course content, refining the course objectives, reasonably increasing the course difficulty and expanding the course depth. It not only enhances students' sense of access, initiative and participation in the classroom, but also improves learners' innovative and entrepreneurial skills, core literacy, management thinking and management abilities.
"MU classroom" informatization teaching tools, timely analysis of the learning situation and teaching according to the material, to achieve "learning before teaching" process transformation. This is an opportunity for education informatization to move into a new era of $5 \mathrm{G}$. (Figure 4) 
Entrepreneurship Training Programme under Project No. 2022002204003.

\section{References}

1. WANG Jinxu, ZHU Zhengwei, LI Maoguo. Blended teaching mode:connotation, meaning and implementation requirements $[\mathrm{J}]$. Higher Architecture Education,2018,27(04):7-12.
2. Robert M. Bernard, Philip C. Abrami. How Does Distance Education Compare With Classroom Instruction? A Meta-Analysis of the Empirical Literature[J]. Review of Educational Research, 2004, 74(3):379-439.

3. Wendy W. Porter, Charles R. Graham, Kristian A. Spring, et al. Blended learning in higher education: Institutional adoption and implementation[J]. Computers \& Education, 2014, 75:185-195. 